PONTIFÍCIA UNIVERSIDADE CATÓLICA DO RIO DE JANEIRO

\title{
Inteligência Emocional
}

\author{
Ana Luiza Leite Oliveira da Silva
}

Trabalho de Conclusão de Curso

Centro de ciênCIAS SOCIAIS - CCS

DePARTAMENTO de AdMINISTRAÇÃo

Graduação em Administração de Empresas 


\title{
Ana Luiza Leite Oliveira da Silva
}

\author{
Inteligência Emocional
}

Trabalho de Conclusão de Curso

Trabalho de Conclusão de Curso, apresentado ao programa de graduação em Administração da PUC-Rio como requisito parcial para a obtenção do titulo de graduação em Administração.

Orientador(a) : Andrea Bittencourt

Rio de Janeiro, novembro de 2016. 


\section{Resumo}

Silva, Ana Luiza Leite Oliveira da. Bittencourt, Andrea. Inteligência Emocional. Rio de Janeiro, 2016. Trabalho de Conclusão de Curso Departamento de Administração. Pontifícia Universidade Católica do Rio de Janeiro.

O presente trabalho relata o nível de Inteligência Emocional (I.E.) dos alunos concluintes do curso de Administração da PUC-Rio no período de 2016.2, porém, o trabalho não tem como objetivo quantificar se os alunos têm ou não nível de I.E. E sim a sua amplitude, isto é, se o nível de I.E. é alto, bastante desenvolvido, se precisa "deslanchar", não é bom ou é baixo. Este trabalho foi realizado com o auxílio de alguns livros e questionários fechados (ferramenta Google Docs).

Palavras- chave

Inteligência Emocional - Empatia - Alunos concluintes 


\section{Abstract}

Silva, Ana Luiza Leite Oliveira da. Inteligência Emocional. Rio de Janeiro, 2016. Trabalho de Conclusão de Curso - Departamento de Administração. Pontifícia Universidade Católica do Rio de Janeiro.

The present study relates the level of Emotional Intelligence (E.I.) of students in senior year of the major Business Administration at PUC-Rio in 2016.2, however the study does not have as a goal to quantify whether the students have a level of E.I. or not. However, its amplitude, in other words, if the level of E.I. is high, quite developed, if is necessary get better, is not good or low. This study was conducted using some books, and closed questionaries (Google Docs).

Key-words

Emotional Intelligence - Empathy - Graduating 


\section{Sumário}

1 O tema e o problema de estudo 1

1.1 Introdução ao tema e ao problema do estudo 1

1.1 Objetivo do estudo 4

1.2 Objetivos intermediários do estudo 4

1.3 Delimitação e foco do estudo 4

1.4 Justificativa e relevância do estudo 4

2 Referencial teórico 6

2.1 Conceitos da I.E. 6

2.2.1 Modelo da I.E. baseado na capacidade (SALOVEY e MAYER, 1990). 7

2.2.2 Modelo Misto da I.E (GOLEMAN, 2007). 8

2.2.2.1 Autoconhecimento 8

2.2.2.2 Autogestão 8

2.2.2.3 Empatia 9

2.2.2.4 Automotivação 9

$\begin{array}{ll}\text { 2.2.2.5 Gestão das Relações } & 10\end{array}$

2.2 Desenvolvimento da I.E (BRADBERRY e GREVAES 2007) 10

2.3.1 Competência Pessoal 12

2.3.2 Competência Social 12

2.3 Inteligência Emocional na Empresa 14

2.4 Teste de Q.E 16

$\begin{array}{lll}\text { 2.4.1 Teste de Q.E } 1 & 16\end{array}$

2.4.2 Teste de Q.E $2 \quad 16$

$\begin{array}{lll}2.4 .3 & \text { Teste de Q.E } 3 & 17\end{array}$

3 Métodos e procedimentos de coleta e de análise de dados do estudo18

$\begin{array}{ll}3.1 \text { Tipos de Pesquisa } & 18\end{array}$

$\begin{array}{ll}3.2 \text { Tratamento de dados } & 18\end{array}$

$\begin{array}{ll}3.3 & \text { Análise de dados } \\ \end{array}$ 
3.4 Limitações do método

4 Apresentação e análise dos resultados 20

4.1 Descrição dos níveis de I.E identificados 20

4.1.1. Autoconhecimento 20

4.1.2. Autogestão 21

4.1.3. Empatia 21

4.1.4. Automotivação $\quad 21$

4.1.5. Gestão das Relações 22

5 Conclusões e recomendações para novos estudos 23

6 Referências $\quad 24$

$\begin{array}{lll}7 & \text { Anexo } 1 & 25\end{array}$

$\begin{array}{llr}8 & \text { Anexo } 2 & 27\end{array}$

9 Anexo $3 \quad 30$ 


\section{0 tema e o problema de estudo}

\subsection{Introdução ao tema e ao problema do estudo}

No início do século $X X$ foram introduzidos teorias e estudos feitos pelo americano Taylor (1903) e Fayol (1916) nos ambientes industriais com o objetivo de melhorar 0 processo produtivo e consequentemente aumentar a produtividade, formas essas de organizações que foram crescendo em função da Revolução Industrial. Chiavenato (2011) afirma que Taylor manteve seus estudos com ênfase nas tarefas, enquanto a principal característica dos estudos de Fayol tinha ênfase na estrutura. Isto é, apesar de terem o mesmo objetivo, cada um tentou alcançá-lo por meios diferentes.

Chiavenato (2011) comenta que as pessoas dentro das organizações eram vistas apenas como meio para se alcançar o objetivo maior, ou seja, até esse momento as abordagens não consideravam os sentimentos, as emoções e as condições que os operários eram submetidos no ambiente de trabalho. Eles tinham que obedecer às ordens sem fazer críticas e sem entender como de fato funcionava o processo produtivo dos produtos que confeccionavam, afinal, o trabalho era executado numa linha de montagem, onde cada funcionário era responsável por uma fase do processo.

Chiavenato (2011, p. 94) aponta que o desenvolvimento das ciências sociais, principalmente da Psicologia, fez com que o pensamento humano mudasse com relação aos relacionamentos na organização. Chiavenato (2011, p. 94) ratifica que a prioridade deixa de ser a máquina e o método de trabalho e passam a ser as pessoas e os grupos sociais, mudando de aspectos técnicos e formais para os aspectos psicológicos e sociológicos.

Como já destacado, Chiavenato (2011, p. 98) percebe a preocupação com as relações humanas. No final da segunda década do século XX, a abordagem humanística surgiu com a necessidade de humanizar e democratizar a administração e livrar os trabalhadores dos conceitos rígidos da teoria clássica. O seu ápice se deu após a conclusão da experiência de Hawthorne realizada por Elton Mayo entre 1927 e 1932.

A experiência de Hawthorne teve por objetivo identificar a correlação entre produtividade e iluminação do local de trabalho. Ao decorrer da experiência os pesquisadores constataram que os resultados da experiência eram afetados por variáveis de caráter psicológico, eles se sobressaíam em relação aos fisiológicos. A influência da experiência de Hawthorne foi muito importante para 
a Teoria Administrativa, pois abalaram os princípios básicos da Teoria Clássica então dominante. $\mathrm{O}$ estudo revelou que:

o nível de produção não é determinado pela capacidade física ou fisiológica do empregado (como afirmava a Teoria Clássica), mas por normas sociais e expectativas grupais, isto é, quanto maior a integração social no grupo de trabalho, tanto maior a disposição de produzir (CHIAVENATO, 2011, p. 101).

Chiavenato (2011, p. 103) ainda salienta, que "os elementos emocionais não planejados e irracionais do comportamento humano merecem atenção especial da Teoria das Relações Humanas. ".

Chiavenato (2011, p. 307) afirma que após a Psicologia ser introduzida na Teoria das Relações Humanas, esta teve seu nome modificado para Psicologia Organizacional, dando abertura para a "entrada" da Teoria Comportamental no final da década de 1940, que tem como objetivo o comportamento do indivíduo, e para compreender como o mesmo se comporta fez-se necessário o estudo da motivação. $\mathrm{O}$ autor ainda declara que os autores behavioristas perceberam que para o administrador compreender como o indivíduo se comporta, era necessário antes identificar o que o motiva a agir de determinada maneira para usá-la ao seu favor, isto é, utilizar-se da motivação de forma a melhorar a qualidade de vida dentro das organizações.

Chiavenato (2011) explica que a Teoria Comportamental tenta mostrar a melhor maneira para se administrar a organização e as pessoas que a compõem, enquanto a Teoria da Contingência compreende o contrário. Segundo essa teoria, o que ocorre dentro de uma organização é decorrente do ambiente, isto é, a organização não existe isoladamente, ela é um sistema aberto e é influenciada constantemente tanto pelo ambiente externo quanto pelo ambiente interno. A forma com que o ambiente externo impacta a organização interfere diretamente em cada setor que a compõe.

Chiavenato (2011) relata que a Teoria da Contingência entende que os atributos de uma organização advêm do ambiente, que a condiciona e a obriga a se adaptar para sobreviver e crescer. Além disso, a organização deve escolher uma tecnologia para se defrontar com esse ambiente de tantas incertezas. E como a organização é constituída de pessoas, a forma como se comportam também é influenciada pelo ambiente e tecnologia escolhida pela organização.

A Teoria da Contingência foi de suma importância para o desenvolvimento dos indivíduos no ambiente de trabalho, foi a partir dela que se passou a aceitar 
a variabilidade humana. As diferenças individuais foram realçadas e passou-se a respeitar a personalidade dos colaboradores, diferente de antes que 0 comportamento era padronizado. Sendo assim, o indivíduo sentiu a necessidade de ser capaz de controlar seus sentimentos e emoções no ambiente de trabalho, de forma a evitar conflitos e gerar boas relações interpessoais e um ambiente de trabalho agradável. Isto é, além do conhecimento técnico, o indivíduo precisa administrar muito bem as suas emoções. Afinal, o indivíduo é constituído de razão e emoção.

Segundo Goleman (2007, p. 60), as pessoas que sabem administrar as suas emoções e reconhecer as do outro, têm mais chances de se sentirem satisfeitas e de perceberem se são mais eficientes em suas vidas, diferente das que não conseguem lidar com suas emoções. Essas acabam sofrendo uma batalha interna que acabam prejudicando a capacidade de se concentrar no trabalho.

Há indícios que atestam que as pessoas emocionalmente competentes, que conhecem e lidam bem com os próprios sentimentos, entendem e levam em consideração os sentimentos do outro. Estas levam vantagem em qualquer setor da vida, seja nas relações afetivas ou assimilando as regras tácitas que governam o sucesso na política organizacional.

Goleman (2007, p. 60) enfatiza que as pessoas com prática emocional bem desenvolvida têm mais probabilidade de se sentirem satisfeitas e de serem eficientes em suas vidas, dominando os hábitos mentais que fomentam sua produtividade; aquelas que não conseguem exercer nenhum controle sobre sua vida emocional travam batalhas internas que sabotam a capacidade de concentração no trabalho e de lucidez de pensamento.

Cooper (1997, p. 19) destaca que o Quociente Emocional (QE) auxilia o Quociente Intelectual (QI), quando é necessário resolver problemas importantes ou tomar uma decisão-chave, e permite que você realize isso de uma maneira melhor e em uma fração de tempo - poucos minutos, ou mesmo segundos, por exemplo, em vez de um dia inteiro ou mais de uma exaustiva sequência ininterrupta e linear de pensamentos que seria necessária para tomar a mesma decisão sem a ajuda do QE. Além disso, as emoções despertam a intuição e a curiosidade, que ajudam a antecipar um futuro incerto e planejar nossas ações de acordo com ele.

A inteligência emocional (I.E.) para os jovens que ingressam no mercado de trabalho é importante porque os auxilia na maneira em como reagem ao falar 
em público sob pressão, e como se colocar no lugar do outro em momento decisivo e na administração das suas emoções pessoais.

Com base no que foi explicitado fez-se a seguinte pergunta de pesquisa: Qual o nível de I.E. dos alunos concluintes do curso de Administração da PUCRio no período de 2016.2?

\subsection{Objetivo do estudo}

A partir da aplicação do modelo de Goleman (2007) pretende-se identificar o nível de I.E. dos alunos concluintes do curso de Administração da PUC-Rio.

\subsection{Objetivos intermediários do estudo}

Definir o construto da I.E. e demonstrar seus pilares, assim como mapear testes que meçam o $\mathrm{QE}$, e ainda selecionar o teste que melhor se adeque ao objetivo do estudo (apenas alunos concluintes atuantes no mercado de trabalho ou não).

\subsection{Delimitação e foco do estudo}

Esse estudo tem como foco os alunos concluintes do curso de Administração da PUC-Rio no período de 2016.2, não se tem a intenção de estudar alunos concluintes de outros cursos e outras instituições de ensino e não se pretende quantificar o nível de I.E, mas a sua amplitude, isto é, se o nível de I.E. é alto, bastante desenvolvido, se precisa "deslanchar", não é bom ou é baixo. Embora relevante o estudo não se propõe a criticar os testes de I.E. quanto à sua aplicabilidade.

\subsection{Justificativa e relevância do estudo}

Notou-se após cursar diversas disciplinas do curso de Administração que a temática em I.E. é pouco trabalhada nas ementas das disciplinas do mesmo curso. Faz-se necessário conscientizar os estudantes da relevância do tema e possivelmente validar teorias para que essas sejam aplicadas pelos mesmos no dia-a-dia. Os gestores das empresas precisam compreender mais sobre o tema e como os seus futuros colaboradores lidam com as emoções para que haja uma interação com mínimo número de conflitos. E a partir disso, poderem refletir sobre que práticas poderão ser adotadas para desenvolver a I.E. Além disso, o 
estudo é relevante também para a sociedade no sentido de conscientizar as pessoas sobre a importância do tema tanto para o crescimento profissional quanto pessoal, servindo de suporte desde a educação de crianças até aos relacionamentos nas organizações. 


\section{Referencial teórico}

Nesta seção são apresentados e discutidos aspectos conceituais e estudos relacionados à I.E. que servirão de base para a análise realizada.

Esta seção está dividida em cinco subseções e aborda, respectivamente, a questão da I.E. no âmbito pessoal e profissional para contextualizar o problema de estudo sobre o nível de I.E. dos alunos concluintes do curso de Administração da PUC-Rio no período de 2016.2. A primeira parte desta seção é destinada a conceituação de afeto, emoções e sentimentos trabalhados por Robbins et al. (1997) para dessa forma demonstrar a definição e evolução da I.E. segundo Salovey e Mayer (1990) e Goleman (2007).

A segunda parte trabalha a conceituação da I.E. desenvolvida pelos mesmos autores.

A terceira parte apresenta um passo-a-passo de como desenvolver a I.E. explicado por Bradberry e Grevaes (2007).

A quarta parte comunica a I.E. dos indivíduos nas empresas.

Por fim a última parte desta seção apresenta o teste de QE adaptado dos testes de Seymor e Shevington (2001) e Denise Dutra (Guia RH).

\subsection{Conceitos da I.E.}

Antes de começarmos a análise, precisamos conceituar três termos que estão intimamente entrelaçados e são confundidos: afeto, emoções e sentimentos. Robbins (2010) conceitua:

Afeto: é um termo genérico que abrange grande número de
sensações experimentadas pelas pessoas, englobando tanto
emoções quanto sentimentos. Geralmente existe a tendência
de associar afeto e, por consequência, seus derivados, como
afetividade e afeição a situações ou experiências positivas,
apesar de poder estar associado igualmente a estados
afetivos, como a insatisfação ou a tristeza.

Emoções: são expressões afetivas intensas dirigidas a alguém ou a alguma coisa. Podemos dizer que as emoções são uma súbita ruptura do equilíbrio afetivo de uma pessoa. Quase sempre são de curta duração e são geralmente acompanhadas de reações fisiológicas, tais como choro, batimento cardíaco acelerado, suores frios ou tremor nas pernas.

Sentimentos: são estados afetivos menos intensos e mais duráveis do que as emoções e que geralmente não requerem um estimulo contextual para se manifestarem. Apesar das diferenças, tanto as emoções como os sentimentos são essenciais para expressarmos a nossa afetividade. 


\subsubsection{Modelo da I.E. baseado na capacidade (SALOVEY e MAYER, 1990).}

A concepção da I.E segundo Salovey e Mayer (1990) luta por definir a I.E dentro dos limites dos critérios standard para uma nova inteligência. $\mathrm{Na}$ sequência da sua investigação contínua, a sua definição inicial da I.E foi corrigida para: "A capacidade de percepcionar emoções, integrar emoções para facilitar o pensamento, compreender emoções e regular as emoções para promover o crescimento pessoal." (SALOVEY e MAYER, 1990).

O modelo baseado na capacidade compreende as emoções como fontes úteis de informação que ajuda os indivíduos a compreender e controlar o meio social que está envolta, ou seja, o seu entorno. O modelo explica que os indivíduos variam na capacidade de processar informação de natureza emocional e na capacidade de processar o aspecto emocional e relacioná-lo numa cognição mais ampla. Esta capacidade é vista a manifestar-se em certos comportamentos adaptativos.

O modelo propõe que a I.E inclua 4 tipos de capacidades:

- Percepcionar Emoções: a capacidade de detectar e decifrar emoções em rostos, fotografias, vozes e artefatos culturais - incluindo a capacidade de identificar as próprias emoções. Percepcionar emoções representa o aspecto básico da I.E., da mesma maneira que torna possível todo o processamento da informação emocional.

- Usar Emoções: a capacidade de aproveitar emoções para facilitar várias atividades cognitivas, tais como pensar e resolver problemas. A pessoa emocionalmente inteligente pode capitalizar em qualquer tarefa ao aproveitar os seus humores, a fim de se adequar melhor à tarefa em mãos.

- Compreender Emoções: a habilidade de compreender a linguagem da emoção e de apreciar complicados relacionamentos entre diferentes emoções. Por exemplo, compreender emoções engloba a capacidade de ser sensível às menores variações entre emoções e a capacidade de reconhecer e descrever como as emoções evoluem no tempo.

- Gerir Emoções: a capacidade de controlar emoções tanto em nós próprios como nos outros, isto é, seria uma autogestão das emoções. Assim sendo, uma pessoa emocionalmente inteligente pode aproveitar emoções, mesmo as negativas e geri-las de forma a atingir os objetivos propostos. 


\subsubsection{Modelo Misto da I.E (GOLEMAN, 2007).}

\subsubsection{Autoconhecimento}

Goleman (2007, p. 70) prefere utilizar o termo autoconsciência, no sentido de permanente atenção ao que estamos sentindo internamente. Nessa consciência auto reflexiva, a mente observa e investiga o que está sendo vivenciado, incluindo as emoções. O autor ainda completa ao dizer que a autoconsciência não é uma atenção que se deixa levar pelas emoções, reagindo com exagero e amplificando a percepção. Ao contrario, é um modo neutro, que mantém a auto reflexividade mesmo em meio às emoções turbulentas.

A consciência das emoções é a aptidão emocional fundamental sobre a qual se fundam outras, como o autocontrole emocional (GOLEMAN, 2007, p. 71).

Goleman (2007, p. 79) termina definindo autoconsciência emocional como a base do aspecto da I.E.: ser capaz de afastar um estado de espirito negativo.

\subsubsection{Autogestão}

Goleman (2007, p. 106) afirma que a autorregulação emocional é a capacidade de controlar um impulso para conseguir chegar a um objetivo, seja montar uma empresa, ou solucionar uma equação algébrica. As constatações deste autor acentuam o papel de como uma capacidade de atingir metas, determinando como as pessoas podem empregar bem ou mal suas outras capacidades mentais.

Goleman (2007, p. 110) explica que da perspectiva da I.E, ser esperançoso significa que não vamos sucumbir numa ansiedade arrasadora, atitude derrotista ou em depressão diante de desafios ou reveses difíceis. $\mathrm{Na}$ verdade, as pessoas esperançosas mostram menos depressão que as outras ao conduzirem suas vidas em busca de suas metas, são em geral menos ansiosas e têm menos distúrbios emocionais.

Goleman (2007, p. 103) esclarece que na medida em que nossas emoções atrapalham ou aumentam nossa capacidade de pensar e fazer planos, de seguir treinando para alcançar uma meta distante, solucionar problemas e coisas assim, elas definem os limites de nosso poder de usar nossas capacidades mentais inatas, e assim determinam como nos saímos na vida. E na medida em que somos motivados por sentimentos de entusiasmo e prazer no que fazemos ou mesmo por um grau ideal de ansiedade, esses sentimentos nos levam ao 
êxito. É nesse sentido que a I.E é uma aptidão mestra, uma capacidade que afeta profundamente todas as outras, facilitando e interferindo nelas.

Goleman (2007, p. 15) diz que enquanto a I.E determina nosso potencial para aprender os fundamentos do autodomínio e afins, nossa competência emocional mostra o quanto desse potencial dominamos de maneira que ele se traduza em capacidades profissionais. Para ser versado em uma competência emocional como o atendimento ao consumidor ou trabalho em equipe, é preciso possuir uma habilidade subjacente nos fundamentos do QE (quociente emocional), especificamente consciência social e gerenciamento de relacionamentos. Mas as competências emocionais são habilidades aprendidas, o fato de uma pessoa possuir consciência social e aptidão para gerenciar relacionamentos não garante que ela tenha dominado o aprendizado adicional necessário para lidar com um cliente a contento ou resolver um conflito. Essa pessoa apenas tem o potencial de se tornar hábil nessas competências.

\subsubsection{Empatia}

Goleman (2007, p. 34) define empatia como ato de compreensão tão seguro quanto à apreensão do sentido das palavras contidas numa página impressa.

A preocupação de Goleman (2007, p. 58) é com um conjunto fundamental dessas "outras características", a inteligência emocional: por exemplo, a capacidade de criar motivações para si próprio e de persistir num objetivo apesar dos percalços; de controlar impulsos e saber aguardar pela satisfação de seus desejos; de se manter em bom estado de espírito e de impedir que a ansiedade interfira da capacidade de raciocinar; de ser empático e autoconfiante.

Goleman (2007, p. 59) reitera que o indivíduo precisa lidar com frustações, controlar emoções e de relacionar-se com outras pessoas.

\subsubsection{Automotivação}

Goleman (2007, p. 32) clarifica que todas as emoções são, em essência, impulsos, legados pela evolução, para uma ação imediata, para planejamentos instantâneos que visam lidar com a vida. A própria raíz da palavra emoção é do latim movere - "mover" - acrescida do prefixo "e", que denota "afastar-se", o que indica que em qualquer emoção esta implícita uma propensão para um agir 
imediato. A automotivação seria o indivíduo ser capaz de utilizar recursos que o faça ficar motivado e não frustrado frente à dificuldades vividas no seu dia a dia.

\subsubsection{Gestão das Relações}

Goleman (2007, p. 13) salienta que a I.E prevalece sobre o QI (quociente intelectual) apenas naquelas áreas "tenras" nas quais o intelecto é relativamente menos relevante para o sucesso nas quais, por exemplo, autocontrole emocional e empatia podem ser habilidades mais valiosas do que aptidões meramente cognitivas.

O indivíduo deve ter a capacidade de saber conviver bem com o outro, isto é, saber se portar e compreender o lado do outro. Afinal, pessoas com habilidades interpessoais sabem como demonstrar suas emoções de forma apropriada e como responder da melhor forma às emoções dos outros.

\subsection{Desenvolvimento da I.E (BRADBERRY e GREVAES 2007)}

Existem atualmente três modelos principais de $\mathrm{QE}$, com dezenas de variações. Cada um deles representa uma perspectiva diferente. $O$ modelo de Salovey e Mayer (1997) se apoia com firmeza na tradição de inteligência concebida pelo trabalho original sobre QI, de um século atrás. E o modelo de Goleman (2007, p.13) se concentra no desempenho no trabalho e na liderança organizacional, misturando a teoria do QE com décadas de pesquisa sobre a modelação de competências que separam indivíduos notáveis dos medianos.

Goleman (2007, p.10) exemplifica que em Illinois existem modelos específicos de aprendizagem em habilidades de Aprendizagem Social e Emocional (SEL em inglês social and emotional learning), os alunos do ensino fundamental devem aprender a reconhecer e classificar com precisão seus sentimentos e como eles o levam a agir. Nas séries do segundo ciclo fundamental, as atividades de empatia devem tornar a criança capaz de identificar as pistas não-verbais de como outra pessoa se sente; nos últimos ciclos do fundamental, elas devem ser capazes de analisar o que gera estresse nelas ou o que as motiva a ter desempenho melhores. $E$ no ensino médio, as habilidades SEL incluem ouvir e falar de modo a solucionar conflitos em vez de agravá-los e negociar saídas em que todos ganhem - Exemplo da I.E em uma escola estabelecidos em todas as séries, desde o jardim de infância até o último ano do ensino médio. Tomando apenas um exemplo de um currículo 
notavelmente detalhado e abrangente, nos primeiros momentos não é possível saber exatamente o que se escrever de experiência, afinal, o indivíduo ainda está no início de sua carreira profissional e não possui muitas experiências relevantes.

Bradberry (2007, p. 28) sintetiza ao dizer que pessoas que aperfeiçoam seu QE têm mais chance de prosperar em situações em que outros fracassam. Apesar de definir nosso comportamento, a I.E continua sendo "algo" intangível para a grande maioria.

Bradberry (2007, p. 28) observa que no início do século $X X$, surgiu um método para medir o QI que permitia distinguir desempenhos médios de excelentes. Os cientistas logo descobriram as limitações dessa abordagem. Muitas pessoas eram incrivelmente inteligentes (em leitura, escrita e matemática), porém limitadas no que se referir a gerir seu comportamento e relacionar-se bem com os outros. Também registraram casos de pessoas com uma inteligência mediana que obtinham excelentes resultados na vida profissional.

Bradberry (2007, p. 28) informa que E.L. Thorndike, professor da Universidade de Columbia foi o primeiro a definir e nomear as aptidões da I.E. Ele criou a expressão "inteligência social", que refletia a habilidade de estabelecer bons relacionamentos. Só na década de 1980 surgiu o método para medir o QE. Pesquisas da Universidade de Yale mostraram que a I.E. afeta a realização pessoal, a felicidade e o sucesso profissional. Isso explica por que duas pessoas com o mesmo QI atingem níveis de sucesso tão diferentes na vida.

Bradberry (2007, p. 30) demonstra que as quatro aptidões da I.E se baseiam em duas competências: a pessoal e a social. A primeira é resultante de sua autoconsciência e seu autocontrole, que aliam a percepção das emoções à maneira de guiar sua conduta. A segunda é consequência de sua consciência social e sua habilidade de administrar relacionamentos; é a aptidão para compreender o comportamento de outras pessoas, assim como a motivação e o direcionamento de suas relações pessoais. Essas duas competências ocorrem juntas com tanta frequência que nem mesmo são percebidas de modo independente. Em geral, uma única aptidão não é suficiente para obter os resultados desejados. 


\subsubsection{Competência Pessoal}

Bradberry (2007, p. 30) alicerça ao dizer que a autoconsciência e o autocontrole são as duas características mais importantes, na medida em que enfocam mais sua individualidade do que sua interação com as outras pessoas. O autor completa ao falar que a autoconsciência permite identificar as emoções no momento em que afloram e compreender as possíveis reações diante de acontecimentos. Além disso, ela aprofunda a percepção de suas reações diante de situações específicas, desafios e relacionamentos pessoais. $O$ autor ainda pondera que um grau elevado de autoconsciência aumenta a tolerância aos sentimentos negativos, e por tabela, ajuda a entender as emoções positivas.

Bradberry (2007, p. 31) firma que a reflexão é a única maneira de compreender o que você está sentindo. As emoções sempre servem a um propósito. Muitas vezes parecem aflorar do nada, mas no fundo sempre há razões que justificam determinadas circunstâncias. É importante descobrir o que provocou determinada reação. Quem atinge esse nível de percepção, em geral, sabe identificar o cerne de um sentimento com rapidez.

\subsubsection{Competência Social}

Bradberry (2007, p. 31) relata que essa aptidão trata de nossa capacidade de entender as pessoas e de nos relacionar com elas. Ela aparece ao lado da consciência social e da capacidade de administrar relacionamentos. Quem tem consciência social compreende as emoções alheias e, com frequência, capta os pensamentos e os sentimentos de outras pessoas. É fácil de deixar dominar pelas próprias emoções quando se desconsidera a perspectiva da outra parte.

Bradberry (2007, p. 32) cita que a administração de relacionamentos resulta das três primeiras aptidões: autoconsciência, autocontrole e consciência social. $\mathrm{O}$ autor aponta que é ela que determina sua capacidade de perceber a si mesmo e os outros e de estabelecer interações com sucesso e garantia de uma comunicação clara, que o levará a abordar qualquer conflito de forma tranquila.

Para Bradberry $(2007$, p. 32) a I.E é o resultado de duas aptidões: a competência pessoal e a competência social. A competência pessoal enfoca mais no indivíduo e se subdivide em autoconsciência e autocontrole, enquanto a competência social aborda a maneira de se comportar com outras pessoas e se subdivide em consciência social e administração de relacionamentos. 
Segundo Bradberry (2007, p. 47) a I.E é tão importante para o sucesso que representa $60 \%$ da produtividade em todos os tipos de trabalho _ ela é o mais forte condutor de liderança e excelência pessoal.

Bradberry (2007, p. 48) assegura que as empresas se beneficiam da I.E, pois colaboradores estimulados exercitam com mais eficácia suas habilidades de liderança, de trabalho em equipe e de captação de novos clientes.

Bradberry (2007, p. 48) enfatiza que as pessoas sabem que a I.E ajuda a ter um desempenho mais eficiente, melhora o relacionamento com os outros e motiva a trabalhar. Isso cria um ambiente em que todos vencem.

Para Bradberry (2007, p. 52) quantificar a I.E representa mais que um exercício prático ou motivacional. Quando conhecemos os pontos fracos e os fortes de nossas próprias aptidões, a experiência de desenvolver a I.E se torna mais relevante e pessoal.

Segundo Bradberry (2007, p. 59) as pessoas podem usar seu QI para ser bem-sucedidas, mas falhar no relacionamento interpessoal, o que as impede de desenvolver seu potencial pleno. $\mathrm{O}$ autor aponta que quando se trabalha com alguém que possui essas características, é fácil ignorar o fato de que seu sucesso advém de sua competência profissional. $O$ autor comenta que quem tem uma baixa pontuação no QE se apoia em seu autocontrole e em sua inteligência para obter êxito no dia-a-dia. Pessoas difíceis extremamente bemsucedidas são uma minoria; cerca de $90 \%$ dos altos executivos possuem um grau elevado de I.E.

Para Bradberry (2007, p. 62) o QE tem uma tendência a aumentar com a idade. Muita gente adquire mais autoconsciência conforme amadurece, passando a ter mais facilidade para controlar as emoções e o comportamento. Os cinquentões, em média, obtêm pontuação $25 \%$ mais elevada em nosso teste do que aqueles na casa dos 20 anos. A tendência é ganhar alguns pontos no grau de I.E a cada década da vida, mas não esqueça que é possível maximizá-la em qualquer idade.

Bradberry (2007, p. 74) define competência pessoal como a capacidade de conhecer a si mesmo e de aproveitar o máximo de seu potencial. Não significa ser perfeito ou ter controle total de suas emoções, mas permitir ser guiado pelos sentimentos.

Bradberry (2007, p. 75) indica que o maior obstáculo para o desenvolvimento da competência pessoal é a propensão a evitar o sofrimento causado pela autoconsciência. $O$ autor demonstra que mais de dois terços das pessoas testadas têm uma enorme dificuldade em assumir suas fraquezas. A 
razão é simples: admiti-lás pode causar sofrimento. O problema é que fugir não resolve nada. Encarar o sofrimento e, por fim, superá-lo é a única maneira de mudar para melhor. Você não pode ser bem-sucedido se ignorar as mudanças.

Bradberry (2007, p. 77) afirma que para "ter um alto nível de autoconsciência significa ser sensível e capaz de identificar a emoção em curso". Dessa forma o mesmo autor documenta que para o indivíduo trabalhar as habilidades da I.E é preciso assumir a responsabilidade pelas dificuldades a serem enfrentadas.

Bradberry (2007, p. 77) enfatiza que a prática das aptidões da I.E nos torna mais eficientes em localizar e usar emoções em nosso benefício em todas as situações. O autor completa que as pessoas com alto grau de I.E são as que começaram cedo nesse processo.

Segundo Bradberry (2007, p. 80) ter autocontrole não significa apenas dominar um comportamento explosivo ou problemático. $O$ autor deduz que 0 maior desafio que as pessoas enfrentam seja o de controlar suas tendências ao longo da vida e usar essa habilidade em diferentes situações.

Bradberry (2007, p. 81) ratifica que a fim de administrar bem seu comportamento, é preciso descobrir as situações que provocam fortes emoções e como agir diante delas.

Bradberry (2007, p. 95) compara ao dizer que quanto mais entendermos nossas emoções, mais fácil será tomar a decisão certa para resolver qualquer problema.

\subsection{Inteligência Emocional na Empresa}

Cooper (1997, p. xvi) explica que o conhecimento da I.E, que cresce exponencialmente, apoiado por centenas de pesquisas e depoimentos de dirigentes, vem ensinando-nos continuamente como aumentar nossa capacidade de raciocínio e, ao mesmo tempo, como utilizar melhor a energia de nossas emoções, a sabedoria de nossa intuição e o poder inerente a nossa capacidade de conexão num nível fundamental com nos mesmos e com aqueles que nos cercam.

Segundo Cooper (1997, p. xvii) A I.E emerge não das cogitações de intelectos refinados, mas das ações do coração humano. O QE não trata de truques de vendas ou de como conseguir uma posição, nem de como dar uma boa aparência às coisas ou da psicologia do controle, da exploração ou na manipulação. O autor define a palavra emoção como a aplicação de 
"movimento", tanto metafórica como literalmente, aos sentimentos fundamentais. Cooper (1997, p. xvii) determina que a I.E é que nos motiva a buscar nosso propósito e potencial únicos e ativa nossas aspirações e valores mais profundos, que deixam de ser algo a respeito de que pensamos e passam a ser vividos. $O$ autor discorre que as emoções foram há muito tempo consideradas tão profundas e poderosas que em latim, por exemplo, eram definidas como motus anima, que significa literalmente "o espírito que nos move.".

Cooper (1997, p. xviii) define I.E como a capacidade de sentir, entender e aplicar eficazmente o poder e a perspicácia das emoções como uma fonte de energia, informação, conexão e influências humanas.

Cooper (1997, p. xviii) explica que quando você utiliza não apenas a mente analítica, mas também suas emoções e intuição, suas sensações e sua I.E o capacitam a percorrer em instantes centenas de possíveis opções e cenários para chegar à melhor solução em questão de segundos em vez de horas. O autor afirma que estudos demonstram não somente a rapidez desse processo, mas a probabilidade de que aqueles que o utilizam terão de descobrir uma resposta tão boa ou melhor do que a que obteriam se tivessem recorrido apenas ao intelecto.

Cooper (1997, p. xix) menciona que ao contrário do que se pensa, as emoções raramente são evasivas, sua interferência quase sempre é inteligente, sensível, benéfica e mesmo sabia. Elas são uma fonte primária de motivação, informação (feedback), força pessoal, inovação e influência. Na maioria das vezes, elas os inspiram e estimulam, ligando-se ao sucesso e à lucratividade.

Cooper (1997, p. xx) acorda que estamos também descobrindo meios de mensurar o relacionamento entre a I.E e a saúde, o trabalho em equipe, a inovação, a produtividade e o lucro.

Cooper (1997, p. 7) enumera algumas das qualidades da IE: energia ativa que anima tudo o que sentimos e valorizamos. Expressamos isso de várias formas, sendo abertos, honestos, íntegros, corajosos e criativos - esforçandonos para transformar mesmo as mais desanimadoras circunstâncias em algo significativo e valioso, para a criação de um novo futuro. Essas são algumas das qualidades da I.E. Quando se pensa nelas, tais qualidades são pouco mais que uma ideologia ou princípios ou boas ideias.

Cooper (1997, p. 13) comenta que em muitos casos, esses são exatamente os gerentes que, por toda a sua ênfase nos frios e rígidos números e resultados financeiros, em sua maioria não são capazes de entender o mecanismo emocional que impulsiona o capital humano e produz o trabalho 
excepcional e criativo, necessário para que uma empresa se oriente em meio à confusão de mudanças no mercado global.

Cooper (1997, p. 16) declara que se não há I.E, sempre que o estresse surge o cérebro humano liga o piloto automático e tem uma tendência inerente para continuar fazendo a mesma coisa, apenas de modo mais intenso. $E$ isso é, na maioria das vezes, exatamente o que não se deve fazer na vida profissional de hoje.

Cooper (1997, p. 18) diz que algumas pessoas são favorecidas com um alto nível de QI e QE. Outras têm escassez de ambos. Essas e outras formas de inteligência intensificam e complementam umas às outras: as emoções estimulam a criatividade, a colaboração, a iniciativa e a transformação; o raciocínio lógico domina os impulsos errantes e alinha propósito com processo, tecnologia com sensibilidade.

As emoções são poderosas organizadoras de pensamento e da nossa ação, e, paradoxalmente, são também indispensáveis para o raciocínio e a racionalidade.

\subsection{Teste de Q.E}

Abaixo são elencados três testes que mede o nível de I.E de um indivíduo, todos foram desenvolvidos com o objetivo de a partir de questões chaves descobrir em qual nível de I.E uma pessoa se enquadra, seria seu nível: alto, bastante desenvolvido, precisa "deslanchar", o grau de empatia e relacionamentos é baixo ou o nível de I.E é baixo.

\subsubsection{Teste de Q.E 1}

Esse teste foi elaborado por Seymor e Shervington, e segue como anexo 1.

\subsubsection{Teste de Q.E 2}

Esse teste foi elaborado pela consultora do Instituto MVC Denize Dutra e segue como anexo 2. 


\subsubsection{Teste de Q.E 3}

Esse teste foi elaborado pela autora desse trabalho com o auxílio dos testes acima mencionados. Foi escolhido perguntas de ambos os testes que melhor se adequem ao objetivo do estudo. Abaixo segue a forma com que o trabalho foi apresentado via Google Docs aos respondentes.

O teste segue como anexo 3 . 


\section{Métodos e procedimentos de coleta e de análise de dados do estudo}

Este estudo é produto de uma pesquisa qualitativa, utilizando a técnica pesquisa exploratória com um levantamento por questionários com as percepções dos indivíduos. A unidade de análise para o trabalho em questão foi a Pontifícia Universidade Católica do Rio de Janeiro (PUC-Rio). Pretende-se identificar o nível de I.E. dos estudantes concluintes do curso de Administração da PUC-Rio no período de 2016.2. O nível é tanto organizacional quanto individual. O tipo de coleta documental foram fontes secundárias (livros, artigos, informações disponíveis na internet, jornais e revistas). O questionário pretende informar sobre as diversas decisões a cerca da forma como este estudo foi realizado.

Está dividida em cinco subseções que informam, respectivamente, sobre as etapas de coleta de dados do estudo realizado, sobre as fontes de informação selecionadas para coleta de informações neste estudo. $\mathrm{Na}$ sequência, informa-se sobre o tratamento dos dados realizados em cada etapa, com respectivas justificativas, sobre as analisar os dados coletados e, por fim, sobre as possíveis repercussões que as decisões sobre como realizar o estudo impuseram aos resultados assim obtidos.

\subsection{Tipos de Pesquisa}

Esse estudo tem como natureza uma pesquisa qualitativa do tipo exploratória, pois a autora do estudo pretende entender melhor através da aplicação de questionários fechados qual o nível de I.E dos respondentes. Sendo assim, foi realizada uma pesquisa de campo (questionários) e a pesquisa bibliográfica ajudou a compor a parte teórica do estudo.

\subsection{Tratamento de dados}

O tratamento de dados será feito através de um questionário fechado. Este questionário fechado foi realizado online via ferramenta Google Docs.

A análise das respostas foi feita com base nas informações do teste de QE que segue como anexo 2, considerando as seguintes pontuações:

91 a 110 pontos: inteligência emocional alta

71 a 90 pontos: inteligência emocional bastante desenvolvida

51 a 70 pontos: precisa "deslanchar" a inteligência emocional 
31 a 50 pontos: o grau de empatia e relacionamentos não é bom

30 pontos ou menos: possui inteligência emocional baixa

\subsection{Análise de dados}

A análise de dados será de conteúdo e usará o conceito de I.E definido por Goleman e seus cinco pilares para fazer a comparação na hora da análise das respostas dos respondentes.

\subsection{Limitações do método}

A limitação da pesquisa qualitativa acontece quando o indivíduo responde o questionário da entrevista de acordo com o que ele pensa que seria o "correto" responder, não demonstrando sua opinião.

A limitação de ser um questionário realizado online faz com que o número de respondentes seja um pouco baixo, visto que as pessoas hoje em dia andam muito ocupadas ou muitas vezes não gostam de responder questionários. O que também pode ocorrer é do indivíduo responder as perguntas de acordo com a sua comodidade, isto é, tem pressa ao respondê-las, ou apenas as responde para ajudar na elaboração do trabalho do autor. 


\section{Apresentação e análise dos resultados}

Este capítulo apresenta e discute os principais resultados alcançados, analisa e discute suas implicações e produz sugestões sobre o estudo previamente selecionado.

A partir da análise dos questionários foi percebido algumas semelhanças com os cinco fatores de Goleman (1995). Para a análise dos resultados, a autora do trabalho visualizou cada questionário individualmente e fez o somatório de pontos, de acordo com esse somatório foi possível identificar de acordo com a análise de resultados estabelecida por Denize Dutra qual dos cinco pilares da I.E o respondente possui. Assim os respondentes foram separados em alguns grupos, pessoas que possuem alto grau de I.E, pessoas que a I.E é bem desenvolvida, pessoas que a I.E precisa "deslanchar", pessoas que possuem baixo grau de empatia e relacionamentos e por fim pessoas que possuem baixa I.E. Porém, de acordo com a pesquisa realizada por meio dos questionários só foi possível obter respondentes para os três primeiros grupos.

\subsection{Descrição dos níveis de I.E identificados}

\subsubsection{Autoconhecimento}

Goleman (2007, p. 71) diz que a consciência das emoções é a aptidão emocional fundamental sobre a qual se fundam outras, como o autocontrole emocional. Isto é, pessoas que possuem autocontrole possuem uma melhor capacidade de se relacionar e consequentemente fazer amizades com maior facilidade.

Goleman (2007, p. 79) termina definindo autoconsciência emocional como a base do aspecto da inteligência emocional: ser capaz de afastar um estado de espírito negativo. Segundo a pesquisa 4 dos 32 respondentes possuem I.E bastante alta como identificado no teste, ou seja, os indivíduos com esse tipo de I.E não tem dificuldades para fazer amigos e nem de relacionar-se com os outros de forma harmoniosa e produtiva.

Sendo assim, é possível dizer que os 4 respondentes possuem um autoconhecimento sendo possível detectar seus pontos fortes e fracos, e têm a capacidade de reconhecer suas emoções de forma a poder adaptá-las conforme a circunstância. 


\subsubsection{Autogestão}

Segundo Goleman (2007) a autogestão é a capacidade de controlar um impulso para conseguir chegar a um objetivo, seja montar uma empresa, ou solucionar uma equação algébrica. Todo indivíduo é capaz de possuir esse tipo de habilidade, basta aprender a se controlar frente às dificuldades enfrentadas. Uma boa forma de conseguir se autocontrolar é o indivíduo entender as emoções que está sentindo e porque se sente dessa forma, e a partir daí o indivíduo deve criar um curso de forma que tais emoções não o levem ao estresse e a falta de controle.

De acordo com a pesquisa tanto os 4 respondentes mencionados anteriormente como outros 25 respondentes que possuem uma I.E bastante desenvolvida possuem esse tipo de habilidade. E segundo o teste utilizado se esses 25 respondentes aprenderem observar as pessoas mais atentamente a I.E poderá ser aprimorada.

\subsubsection{Empatia}

A capacidade de se colocar no lugar de outra pessoa antes de tomar uma atitude é um dos pontos mais relevantes do Goleman (2007). Afinal, ninguém é obrigado pensar como outra pessoal, isto é, cada indivíduo tem seus próprios pensamentos e opiniões. É bem provável que dependendo da circunstância é possível que mais de uma pessoa pense da mesma forma, por isso dentro das organizações existem muitas reuniões para as pessoas exporem suas opiniões e entrarem em um consenso.

Goleman (2007, p. 59) reitera que o indivíduo precisa lidar com frustações, controlar emoções e de relacionar-se com outras pessoas. Assim, podemos compreender que tanto os 4 respondentes que possuem I.E bastante alta como os 25 respondentes de possuem I.E bastante desenvolvida possuem esse tipo de habilidade. Afinal, esses indivíduos são capazes de fazer amigos com facilidade e com um pouco mais de atenção das pessoas eles podem aprimorar um pouco mais a I.E.

\subsubsection{Automotivação}

Segundo Goleman (2007) as pessoas com I.E são motivadas pela satisfação interior. A pessoa com automotivação procura fazer o seu trabalho da melhor maneira possível e ama o seu trabalho. A automotivação seria 0 
indivíduo ser capaz de utilizar recursos que o faça ficar motivado e não frustrado frente à dificuldades vividas no seu dia a dia.

De acordo com a pesquisa realizada somente os 29 respondentes mencionados anteriormente possuem esse tipo de habilidade, pois os outros 3 respondentes têm uma I.E que precisa "deslanchar". Esses indivíduos precisam conversar mais consigo mesmo, ouvir o que os outros dizem com sinceridade sobre eles, treinar seus sentimentos de empatia e desta maneira poderem observar com mais respeito os defeitos das outras pessoas.

\subsubsection{Gestão das Relações}

De acordo com Goleman (2007) a pessoa tem boa relação interpessoal consegue administrar seus relacionamentos de forma clara e por consequência tem a capacidade de trabalhar melhor em equipe. Dentro do construto de I.E é de suma importância que o indivíduo tenha a capacidade de saber conviver bem com o outro, isto é, saber se portar e ver o lado do outro. Afinal, pessoas com habilidades interpessoais sabem como demonstrar suas emoções de forma apropriada e como responder da melhor forma às emoções dos outros.

A partir da pesquisa realizada por meio dos questionários é possível compreender que todos os 32 respondentes possuem esse tipo de habilidade, claro que não completamente. Os 25 respondentes possuem a habilidade de se relacionar plenamente, os 4 respondentes apesar de possuírem uma I.E bastante alta, ainda precisam aprimorar as suas relações e os outros 3 respondentes possuem a habilidade de gerir relações um pouco menor que os outros respondentes e por isso precisam prestar um pouco mais de atenção nas outras pessoas, e olharem um pouco menos para si mesmos. 


\section{Conclusões e recomendações para novos estudos}

O objetivo dessa pesquisa era identificar os níveis de inteligência pessoal que os alunos concluintes do curso de administração da PUC-Rio no período de 2016.2 possuíam. Para chegar ao objetivo, o trabalho consistia em definir o construto de Inteligência Emocional, assim como seus pilares e por meio do modelo de Goleman identificar os níveis da I.E.

Para isso, foi feito uma pesquisa com o auxílio de um questionário fechado por meio da ferramenta Google Docs oferecida online. Com o auxílio do referencial teórico e a pesquisa realizada foi possível chegar ao objetivo final com êxito. Os sujeitos foram selecionados pela acessibilidade da autora e a partir daí foi realizado um questionário fechado como mencionado anteriormente com base em outros dois testes realizados por Seymor e Shervington e Denize Dutra.

Ao analisar as respostas dos alunos foi observado que todos possuem um grau de inteligência emocional, porém em níveis diferentes. Grande parte deles possui uma I.E bastante alta o que significa que não há dificuldades para se relacionar com outras pessoas, ou seja, esses indivíduos são capazes de fazer amizade facilmente. Já os outros sete alunos respondentes também possuem I.E, mas com o nível menor, o que demonstra que eles precisam aprimorar a sua I.E de acordo com as circunstâncias do dia a dia, assim como tentar manter boas relações. O ideal seria que todos tivessem um alto grau de I.E, pois essa é importante para que a pessoa consiga lidar melhor com situações desconfortáveis que interfiram nos sentimentos. 


\section{Referências}

BRADBERRY, Travis; GREVAES, Jean. Desenvolva a sua inteligência emocional: tudo o que você precisa saber para aumentar o seu Q.E. Tradução Marisa Motta. Rio de Janeiro: Sextante, 2007.

ROBBINS, STEPHEN P. Comportamento Organizacional. 14. Ed. Tradução Rita de Cássia Gomes. São Paulo: Pearson Prentice Hall, 2010.

SALOVEY, P.; MAYER, JOHN D. Emotional Intelligence. Baywood Publishing Co. Inc. 1990.

CHIAVENATO, Idalberto. Introdução à teoria geral da administração. 8. ed. total. rev. atual. Rio de Janeiro: Elsevier, 2011.

COOPER, Robert; SAWAF, Ayman. Inteligencia Emocional na empresa Robert K Cooper. 2. ed. Tradução Ricardo Inojosa; Sonia T. Mendes Costa. Rio de Janeiro: Campus, 1997.

GOLEMAN, D. Inteligência emocional: a teoria revolucionária que redefine o que é ser inteligente. 10. ed. Rio de Janeiro: Objetiva, 2007.

SEYMOUR, John; SHERVINGTON, Martin. Como usar a inteligência emocional: seu guia de estratégia pessoal. São Paulo: Pubifolha, 2007.

WEISINGER, Hendrie. Inteligência Emocional no Trabalho: como aplicar os conceitos revolucionários da I.E. nas suas relações profissionais, reduzindo 0 stress, aumentando sua satisfação, eficiência e competitividade. 7. ed. Rio de Janeiro: Objetiva, 1997.

TESTE de inteligência emocional. IQ Elite. Disponível em: $<$ https://www.iqelite.com/pt-br/eq-emotional-intelligence-test/>. Acessado dia 11 de novembro de 2016.

AUTODIAGNÓSTICO: teste sua inteligência emocional. Disponível em <http://www.guiarh.com.br/z84.htm>. Acessado dia 08 de setembro. 


\section{Anexo 1}

Seja o mais honesto possível: se a resposta for "nunca", marque a opção 1; se for "sempre", marque a 4 , e assim por diante. Some os resultados e compare com a escala. Use as respostas para identificar áreas que precisam melhorar.

1. Sou consciente dos meus sentimentos, de modo a poder trabalhalos.

( ) 1 ( ) 2 ( ) 3 ( ) 4

2. Procuro escolher, adotar e manter estados emocionais positivos.

( ) 1 ( ) 2 ( ) 3 ( ) 4

3. Influencio o estado emocional das pessoas, para melhorar sua performance.

( ) 1 ( ) 2 ( ) 3 ( ) 4

4. Penso em maneiras de influenciar outras pessoas de modo eficiente.

( ) 1 ( ) 2 ( ) 3 ( ) 4

5. Trabalho para resolver potenciais conflitos com outras pessoas.

( ) 1 ( ) 2 ( ) 3 ( ) 4

6. Imagino como um mentor poderia abordar uma situação desafiadora.

( ) 1 ( ) 2 ( ) 3 ( ) 4

7. Avalio meus pressupostos limitadores numa situação problemática.

( ) 1 ( ) 2 ( ) 3 ( ) 4

8. Penso cuidadosamente sobre o ponto de vista e a perspectiva de outras pessoas.

( ) 1 ( ) 2 ( ) 3 ( ) 4

9. Dou um passo atrás e revejo situações a partir de um ponto de vista externo.

( ) 1 ( ) 2 ( ) 3 ( ) 4

10. Dedico tempo para ensaiar mentalmente antes de um evento crítico iminente.

( ) 1 ( ) 2 ( ) 3 ( ) 4

11. Reservo tempo na minha agenda para me concentrar no autodesenvolvimento. 
( ) 1 ( ) 2 ( ) 3 ( ) 4

12. Penso sobre meus valores centrais e em estratégias para evoluir na carreira.

( ) 1 ( ) 2 ( ) 3 ( ) 4

\section{Análise}

Agora que você completou o teste, some o seu total de pontos e verifique a avaliação correspondente. Independentemente do nível de desempenho que você atinja, há sempre espaço para melhorar.

12-24: Você tem potencial considerável para melhorar seu desempenho através das habilidades em PNL.

25-36: Você claramente tem pontos fortes e irá beneficiar-se consideravelmente do foco no desenvolvimento das áreas fracas.

37-48: Você tem forte capacidade de inteligência emocional, mas para se tornar um executivo de sucesso precisa continuar desenvolvendo as habilidades de líder e administrador. 


\section{Anexo 2}

Sou uma pessoa...

1. ... que persiste quando está frente a um novo desafio, não desistindo nas primeiras dificuldades...

( ) Sempre

( ) Quase Sempre

( ) Às vezes

( ) Raramente

( ) Jamais

2. ... que procura se colocar no lugar do outro, sendo compreensiva em relação aos momentos difíceis de outra pessoa...

( ) Sempre

( ) Quase Sempre

( ) Às vezes

( ) Raramente

( ) Jamais

3. ... que consegue manifestar suas emoções de acordo com as pessoas, situações e o momento oportuno...

( ) Sempre

( ) Quase Sempre

( ) Às vezes

( ) Raramente

( ) Jamais

4. ... que consegue controlar suas emoções, mantendo a calma nos momentos difíceis...

( ) Sempre

( ) Quase Sempre

( ) Às vezes

( ) Raramente

( ) Jamais

5. ... que tem uma visão realista de si mesmo, com adequada percepção de suas potencialidades e limitações...

( ) Sempre

( ) Quase Sempre

( ) Às vezes

( ) Raramente 
( ) Jamais

6. ... que consegue superar seus sentimentos de frustração quando alguma coisa não dá certo, procurando aprender com as experiências negativas...

( ) Sempre

( ) Quase Sempre

( ) Às vezes

( ) Raramente

( ) Jamais

7. ... que quando tem alguma dificuldade com outra pessoa, procura conversar diretamente com ela, evitando fofocas e mal entendido...

( ) Sempre

( ) Quase Sempre

( ) Às vezes

( ) Raramente

( ) Jamais

8. ... que é muito difícil perder a paciência com as pessoas de que gosto. Se perco, logo recupero e me arrependo de ter perdido...

( ) Sempre

( ) Quase Sempre

( ) Às vezes

( ) Raramente

( ) Jamais

9. ... que consegue expressar suas opiniões de forma clara e percebe que é ouvida com atenção...

( ) Sempre

( ) Quase Sempre

( ) Às vezes

( ) Raramente

( ) Jamais

10. ... que se sente segura diante das outras pessoas...

( ) Sempre

( ) Quase Sempre

( ) Às vezes

( ) Raramente

( ) Jamais 
Avaliação do Resultado

\begin{tabular}{|l|l|l|l|l|}
\hline Jamais & Raramente & Às vezes & Quase Sempre & Sempre \\
\hline 1 & 2 & 3 & 4 & 5 \\
\hline
\end{tabular}

41 a 50 pontos: sua inteligência emocional é bastante alta. Você não deve ter dificuldades para fazer amigos, e nem de relacionar-se com os outros de forma harmoniosa e produtiva.

31 a 40 pontos: sua inteligência emocional é bastante desenvolvida, mas se você aprender a observar atentamente as pessoas poderá desenvolvê-la ainda mais.

21 a 30 pontos: sua inteligência emocional precisa "deslanchar". Converse um pouco mais consigo mesmo, ouça o que os outros dizem com sinceridade de você. Treine seus sentimentos de empatia e aprenda a observar com mais cuidado os defeitos dos outros.

11 a 20 pontos: seu grau de empatia e relacionamentos não é bom. Procure ouvir mais e falar menos. Saiba gostar até mesmo de particularidades que outras pessoas apresentam e que você crítica.

10 pontos ou menos: sua inteligência emocional é bastante baixa. Procure compartilhar mais seus sentimentos e ideias. Acredite que melhorar seus relacionamentos não é difícil, mas exige trabalho persistente, e muita disponibilidade para o outro. Procure aprender com todas as experiências, mesmo que sejam negativas, evitando repetir situações que provocam frustrações. 


\section{Anexo 3}

Meu nome é Ana Luiza Leite e estou concluindo o último período do curso de Administração na Pontifícia Universidade do Rio de Janeiro - PUC. Para o meu trabalho final de curso estou realizando uma pesquisa, cujo tema é Inteligência Emocional.

Para tal é muito importante a sua participação, respondendo as perguntas abaixo. Não é necessário se identificar e as informações são sigilosas, servindo apenas para o término da minha monografia.

Assinale a opção mais próxima de sua experiência. Seja o mais honesto possível.

1. Sou consciente dos meus sentimentos, de modo a poder trabalhá-los.
( ) Jamais
( ) Raramente
( ) Às vezes
( ) Quase sempre

\section{( ) Sempre}

2. Procuro escolher, adotar e manter estados emocionais positivos.

( ) Jamais ( ) Raramente ( ) Às vezes ( ) Quase sempre ( ) Sempre

3. Influencio o estado emocional das pessoas, para melhorar suas performance.

( ) Jamais ( ) Raramente ( ) Às vezes ( ) Quase sempre ( ) Sempre

4. Sou uma pessoa que procura se colocar no lugar do outro sendo compreensiva em relação aos momentos difíceis de outra pessoa .

( ) Jamais ( ) Raramente ( ) Às vezes ( ) Quase sempre ( ) Sempre

5. Trabalho para resolver potenciais conflitos com outras pessoas.

( ) Jamais ( ) Raramente ( ) Às vezes ( ) Quase sempre ( ) Sempre

6. Sou uma pessoa que consegue manifestar suas emoções de acordo com as pessoas, situações e momento o oportuno.

( ) Jamais ( ) Raramente ( ) Às vezes ( ) Quase sempre ( ) Sempre 
7. Sou uma pessoa que consegue controlar suas emoções, mantendo a calma nos momentos difíceis.

\section{( ) Jamais ( ) Raramente ( ) Às vezes ( ) Quase sempre ( ) Sempre}

8. Penso cuidadosamente sobre o ponto de vista e a perspectiva de outras pessoas.

( ) Jamais ( ) Raramente ( ) Às vezes ( ) Quase sempre ( ) Sempre

9. Dou um passo atrás e revejo situações a partir de um ponto de vista externo.

( ) Jamais ( ) Raramente ( ) Às vezes ( ) Quase sempre ( ) Sempre

10. Dedico tempo para ensaiar mentalmente antes de um evento crítico iminente.

( ) Jamais ( ) Raramente ( ) Às vezes ( ) Quase sempre ( ) Sempre

11. Reservo tempo na minha agenda para me concentrar no autodesenvolvimento.

( ) Jamais ( ) Raramente ( ) Às vezes ( ) Quase sempre ( ) Sempre

12. Sou uma pessoa que consegue superar seus sentimentos de frustração quando alguma coisa não dá certo, procurando aprender com as experiências negativas.

( ) Jamais ( ) Raramente ( ) Às vezes ( ) Quase sempre ( ) Sempre

13. Sou uma pessoa que se sente segura diante das outras pessoas.

( ) Jamais ( ) Raramente ( ) Às vezes ( ) Quase sempre ( ) Sempre

14. Sou uma pessoa que consegue expressar suas opiniões de forma clara e percebe que é ouvida com atenção.

( ) Jamais ( ) Raramente ( ) Às vezes ( ) Quase sempre ( ) 
15. Sou uma pessoa que quando tem alguma dificuldade com outra pessoa, procura conversar diretamente com ela, evitando fofocas e mal entendido.

\section{( ) Jamais ( ) Raramente ( ) Às vezes ( ) Quase sempre ( ) Sempre}

16. Penso em maneiras de influenciar outras pessoas de modo eficiente.

( ) Jamais ( ) Raramente ( ) Às vezes ( ) Quase sempre ( ) Sempre

17. Imagino como um mentor poderia abordar uma situação desafiadora.

( ) Jamais ( ) Raramente ( ) Às vezes ( ) Quase sempre ( ) Sempre

18. Avalio meus pressupostos limitadores numa situação problemática.

( ) Jamais ( ) Raramente ( ) Às vezes ( ) Quase sempre ( ) Sempre

19. Penso sobre meus valores centrais e em estratégias para evoluir na carreira.

( ) Jamais ( ) Raramente ( ) Às vezes ( ) Quase sempre ( ) Sempre

20. Sou um pessoa que persiste quando está frente a um novo desafio, não desistindo nas primeiras dificuldades.

( ) Jamais ( ) Raramente ( ) Às vezes ( ) Quase sempre ( ) Sempre

21. Sou uma pessoa que tem uma visão realista de si mesmo, com adequada percepção de suas potencialidades e limitações.

( ) Jamais ( ) Raramente ( ) Às vezes ( ) Quase sempre ( ) Sempre

22. Sou uma pessoa que é muito difícil perder a paciência com as pessoas de que gosto. Se perco, logo recupero e me arrependo de ter perdido.

( ) Jamais ( ) Raramente ( ) Às vezes ( ) Quase sempre ( ) Sempre 